1

2

\title{
Estimated dietary intake of polyphenols in European adolescents: the HELENA study
}

Ratih Wirapuspita Wisnuwardani ${ }^{1,2}$, - Stefaan De Henauw ${ }^{1}$ - Odysseas Androutsos ${ }^{3}$ - Maria Forsner ${ }^{4,5}$ - Frédéric Gottrand $^{6}$ - Inge Huybrechts ${ }^{1,7}$ - Viktoria Knaze ${ }^{7}$ - Mathilde Kersting ${ }^{8}$ - Cinzia Le Donne ${ }^{9}$ - Ascensión Marcos ${ }^{10}$ Dénes Molnár ${ }^{11}$ - Joseph A. Rothwell ${ }^{7}$ - Augustin Scalbert ${ }^{7}$ - Michael Sjöström ${ }^{12}$ - Kurt Widhalm ${ }^{13}$ - Luis A. Moreno ${ }^{14}$ - Nathalie Michels ${ }^{1}$

${ }^{1}$ Department of Public Health, Faculty of Medicine and Health Sciences, Ghent University, C.Heymanslaan 10-4K3, 9000 Ghent, Belgium

${ }^{2}$ Department of Public Health Nutrition, Faculty of Public Health, Mulawarman University, Samarinda, East Kalimantan

${ }^{3}$ Department of Nutrition and Dietetics, Harokopio University, Athens, Greece

${ }^{4}$ Department of Nursing, Umeå University, Sweden

${ }^{5}$ School of Education, Health and Social Sciences, Dalarna University, Falun, Sweden

${ }^{6}$ Inserm U995, Université Lille 2, Lille, France

${ }^{7}$ International Agency for Research on Cancer, World Health Organization, 150 Cours Albert Thomas, 69372 Lyon Cedex 08, France

${ }^{8}$ Research Department of Child Nutrition, Pediatric University Clinic Bochum, Ruhr-Universität Bochum Bochum, Germany

${ }^{9}$ CREA Research Centre for Food and Nutrition, Via Ardeatina, 546, 00178 Rome, Italy

${ }^{10}$ Immunonutrition Research Group, Department of Metabolism \& Nutrition, Institute of Food Science, Technology and Nutrition, Madrid, Spain

${ }^{11}$ Department of Pediatrics, University of Pécs, Pécs, Hungary

${ }^{12}$ Department of Bioscience and Nutrition, Karolinska Institutet, Stockholm, Sweden

${ }^{13}$ Department of Pediatric, Division of Clinical Nutrition, Medical University of Vienna, Vienna, Austria

${ }^{14}$ GENUD (Growth, Exercise, Nutrition and Development) Research Group, Faculty of Health Science, University of Zaragoza, Edificio del SAI, C/Pedro Cerbuna s/n, 50009 Zaragoza, Spain

\section{Abstract}

Purpose Knowledge about polyphenols intakes and their determinants among adolescents might be helpful for planning targeted prevention strategies at an early age.

Methods In the European multicenter cross-sectional HELENA study of 2006-2007, 2428 subjects (47 \% boys) had data on dietary intake of polyphenols from two non-consecutive 24 hour recalls via linking with the Phenol-Explorer database. Differences by sex, age, country, BMI, maternal education, paternal education, family affluence, smoking status, alcohol use, and physical activity were explored by linear regression.

Results Median, lower and upper quartiles of polyphenol intakes were 326, 167 and $564 \mathrm{mg} / \mathrm{d}$, respectively. Polyphenol intake was significantly higher in the oldest (16-17.49 years), girls, non-Mediterranean countries, lowest BMI, highest paternal education, and alcohol consumers. Main food contributors were fruit (23\%, mainly apple and pear i.e. $16.3 \%$ ); chocolate products (19.2\%); and fruit and vegetable juices (15.6\%). Main polyphenol classes were flavonoids (75$76 \%$ of total) and phenolic acids (17-19\% of total). The three most consumed polyphenols were proanthocyanidin polymers ( $>10$ mers), hesperidin, and proanthocyanidin 4-6 oligomers.

Conclusion The current study provided for the first time numbers on the total polyphenol intake and their main food sources in a heterogeneous group of European adolescents. Major differences with adult populations are the lower polyphenol consumption and the major food sources, such as chocolate and biscuits. The discussed determinants and polyphenol types already point to some important population groups that need to be targeted in future public health initiatives.

Keywords Polyphenol · Consumption · Food contributors · HELENA · Determinants · Mediterranean 


\section{Introduction}

49 Polyphenols are bioactive compounds which are widely distributed in plant-based foods such as vegetables, fruit, cocoa,

50 tea, coffee and wine [1]. Polyphenols represent a very diverse group of compounds with over 500 different molecules

51 identified in foods, which can be divided into four main classes, according to their chemical structure: flavonoids,

52 phenolic acids, stilbenes and lignans [2]. The chemical structure affects the polyphenol absorption in the gut,

53 bioavailability and possibly their health effects [3]. Over the last 20 years, there has been great interest in the potential

54 health benefits of polyphenols, such as antioxidant, anti-inflammatory and anti-carcinogenic effects [4]. A literature

55 review has shown an inverse association between polyphenol intake and risk of hypertension among 2725 Polish adults

56 during a 2-4 years follow up study [5]; a positive association with HDL level in 500 Italian adults [6], and a reduced

57 risk for type 2 diabetes in 3400 elderly at high risk for cardiovascular disease [7]. Although current evidence did not

58 show any classical deficiencies due to low polyphenol intakes, recently they have been discussed as 'lifespan essentials'

59 as they are needed throughout the full lifespan in order to reduce the risk of a range of chronic diseases $[8,9]$.

60 Some descriptive data on the intake of polyphenols is already available on population-level. A recent study identified

61 the mean dietary intake of polyphenols as 377 (s.e. 15) mg/d among adults and elderly in Sao Paulo. Higher mean

62 dietary intake of polyphenols was found among men, who were white, in normal weight, and in the higher physical

63 activity groups [10]. A study of people with type 2 diabetes in Italy reported that the mean total polyphenol intake was

$64683 \pm 6 \mathrm{mg} /$ day and polyphenol intake increased with age and education level and decreased with BMI [11]. Another

65 study from Europe revealed that mean total polyphenol intake among adults was the highest in Aarhus-Denmark (1786

$66 \mathrm{mg} /$ day in men and $1626 \mathrm{mg} /$ day in women) and the lowest in Greece (744 mg/day in men and $584 \mathrm{mg} /$ day in women)

67 [12]. In all three studies, coffee was the most important food source of total polyphenols. However, there is no

68 descriptive total polyphenol intake study available in adolescents, although a few studies exist on specific polyphenols

69 in single-country studies [13-15]. Adolescence is a critical period that can affect adult chronic diseases, so dietary

70 intake during adolescence may indicate adult lifestyle and health [16]. For this reason, the identification of the intake

71 of polyphenols among adolescents is important and might be helpful for interventions in promoting healthy eating

72 behavior and preventing dietary-related chronic diseases.

73 Therefore, the purpose of the present study is to estimate European adolescent's dietary intake of polyphenols, the

74 main food contributions and socio-demographic differences using the Phenol-Explorer database as the most complete

75 polyphenol database currently published [17]. The "Healthy Lifestyle in Europe by Nutrition in Adolescence Cross-

76 Sectional Study (HELENA-CSS) study provides the opportunity to explore polyphenol intake among European

77 adolescents by detailed dietary recall data.

\section{Material and Methods}

\section{Study population}

81 The HELENA study is a multicenter study on lifestyle and nutrition among adolescents from 10 European cities:

82 Athens and Heraklion (Greece), Dortmund (Germany), Ghent (Belgium), Lille (France), Pecs (Hungary), Rome (Italy), 
Stockholm (Sweden), Vienna (Austria), and Zaragoza (Spain). The survey was conducted from October 2006 to December 2007, in 3528 adolescents aged 12.5-17.5 years, randomized and stratified by geographical location, age and socio-economic status. Details on specific methods have been reported elsewhere $[18,19]$. The participants and their parents provided written informed consent and the study protocol was approved by the ethics committee of each city involved [20].

Data on food intake from Heraklion and Pecs were not available (i.e. two 24-h dietary recalls and a FFQ) for the present analysis. Furthermore only 2428 adolescents from 8 European cities, who had also completed two non-consecutive 24$\mathrm{h}$ dietary recalls were included in the present analysis.

\section{Dietary, socio-demographic and lifestyle information}

Dietary data were retrieved from a 24-hour recall on 2 non-consecutive days, within a time-span of 2 weeks, but not on Fridays and Saturdays, using HELENA-Dietary Assessment Tool (DIAT). HELENA-DIAT consists of six meal occasions and adolescents were invited to select all food items from a standardized menu structure. Quantitatively detailed information was collected using household measurements or pictures of portion sizes for each selected item [21,22]. Foods reported in the 24-h recalls were linked to the German Food Code and Nutrient Data Base (Bundeslebensmittelschlüssel, BLS, version II.3.1) [23] to assess energy and nutrient intakes.

Collected demographic data included information on sex, age, city and socio-economic status which was examined by parental education and by the Family Affluence Scale (FAS). Parental education level of mother and father were reported using the International Standard Classification of Education (ISCED) classification [24] as "lower education", "higher secondary education" and "university education". A refitted version of the FAS [24] was used as an indicator of the adolescent's material conditions in family. FAS was scored from 0-4 (low FAS score) and 5-8 (high FAS score) based on adolescents' report on internet availability at home ( 0 no, 1 yes), family car ownership (0-3 depending on amount), computer ownership (0-3 depending on amount) and having one's own bedroom ( 0 no, 1 yes). Based on questionnaire data, smoking status, alcohol status and physical activity (hours/week) were computed. . Weight status was classified following the International Obesity Task Force [25] based on measured weight and height. The cities (Athens in Greece, Roma in Italy, and Zaragoza in Spain) were considered as Mediterranean (MED), while Dortmund in Germany, Ghent in Belgium, Lille in France, Stockholm in Sweden, and Vienna in Austria were considered as nonMED.

\section{Estimation of polyphenol intake}

Data on the polyphenol content in food were assessed using the Phenol-Explorer database (www.phenol-explorer.eu), which contains four main polyphenol classes: flavonoids, phenolic acids, stilbenes, lignans and a number of minor polyphenols (described as "other polyphenols" in this manuscript) like tyrosols, alkylphenols (mainly alkylresorcinols), and alkylmethoxyphenols $[12,26]$. Polyphenol content values described in the Phenol-Explorer database are obtained by different analytical methods. For most compounds, data used for this work were obtained by 'chromatography', except for lignans and for phenolic acids in some specific foods (cereals, walnuts, olives and legumes) that were 
measured by 'chromatography after hydrolysis'. Some foods that could contain polyphenols that were present in HELENA-DIAT, but not in the Phenol-Explorer database, such as margarine, palm oil and coconut milk were excluded from the database. Complex foods were calculated according to their ingredients in the recipes. Some processed foods are already food entries in the Phenol-Explorer database, such as tea infusion and fruit juices so no additional retention factors were needed for those processed foods. Processed foods, which are not in the Phenol-Explorer database, such as canned foods and pre-packaged meals were estimated based on the percentages of ingredients. Vegetable oil was estimated as the combination of sunflower oils, corn oils and soy oils. Composition of coffee, herbal tea and olive oil was calculated based on common brands in the country of study. Individual polyphenol intake was calculated by multiplying individual polyphenols content in each food item by the daily consumption of each food. Total polyphenol intake was estimated as the sum of intakes of the individual polyphenols.

\section{Statistical analyses}

Data were presented as means, standard errors, percentages, medians and the 25th and 75th percentiles, as appropriate. The dietary polyphenol intakes were described as absolute intake (mg/day), whereas the contribution of each polyphenol class and subclass to the total polyphenol intake was reported as percentage of total polyphenol intake. Median and the 25th and 75th percentiles were used as measures of central tendency and variability of total polyphenol intake. The general linear models were used to compare differences in polyphenol intakes by sex, age, European region, BMI, maternal education, paternal education, FAS, smoking status, alcohol use, and physical activity. Using energyadjusted polyphenol intake in testing determinants of polyphenol intake retrieved similar results (data not shown). Regression adjustment for sex, age, European region, energy intake, and month of 24-hour recall was performed. Square root-transformation of polyphenol intakes was performed to fit normality when required. Differences in daily consumption of food groups were tested by Mann-Whitney U-test. Reported P-value $<0.05$ (two-tailed) was considered significant. Analyses were processed using Statistical Package for Social Science (SPSS, version 23).

\section{Results}

Overall polyphenol intake

Mean, median, lower quartile and upper quartile of polyphenol intakes for the whole population were 329 (adjusted for sex, age European region, energy intake and month of 24-hour recall), 326, 167 and $564 \mathrm{mg} /$ day, respectively. The 5th and 95th percentiles were 42 and $1163 \mathrm{mg} /$ day, respectively (Supplemental Figure 1). Mean energy-adjusted polyphenol intake was $160 \mathrm{mg} / \mathrm{day} / 1000 \mathrm{kcal}$. The highest total polyphenol intake was in Ghent (in boys $588 \mathrm{mg} /$ day) and in Vienna (in girls $508 \mathrm{mg} /$ day), whereas the lowest intake in both sexes was in Zaragoza (in boys $212 \mathrm{mg} /$ day and in girls $203 \mathrm{mg} /$ day) (Figure 1).

\section{$\underline{\text { Socio-demographic and lifestyle determinants }}$}

The mean intakes of total polyphenols and polyphenol classes are shown according to socio-demographic and lifestyle characteristics in Table 1. Total polyphenol intake was depending on age, sex, European region, BMI, maternal education, paternal education, FAS, smoking status and alcohol intake. The intake of total polyphenols and flavonoids was higher in girls than in boys. Increases by age (independent of energy intake) were seen for total polyphenols, 
152

153

154

phenolic acids and other polyphenols. Non-MED countries ( $457 \mathrm{mg} /$ day) had a higher intake of total polyphenols than MED countries ( $275 \mathrm{mg} /$ day), due to higher flavonoid and phenolic acid intake but the intake of lignans and stilbenes were higher in MED countries than non-MED countries. Adolescents with underweight, a higher parental education, low FAS score or who drank alcohol showed the highest intakes of total polyphenols, mainly due to higher flavonoid intake.

\section{Food group contributions}

Daily consumption of food groups is presented in table 2 to compare food intakes between MED countries and non-MED countries. Many food groups were significantly different, except stalk vegetables, sprout, stone fruits, dairy products, sugar, honey, jam and syrup, other non-alcoholic beverages, wine, and soy products. The contribution of food groups to total polyphenols and each polyphenol class is shown in Table 3. In MED and non-MED countries, the main dietary sources for total polyphenols were fruit ( $24 \%$ and $22 \%$, respectively), chocolate products ( $21 \%$ and $19 \%$, respectively); fruit and vegetable juices (18\% and $15 \%$, respectively). In the fruit group, apple/pear was the largest contributor to total polyphenol intake (14-17\%). Other important contributors were cereal products, cakes/biscuits and coffee/tea (tea was a larger contributor in non-MED while coffee in the MED countries). For flavonoids, all trends were the same. Coffee was the primary food source to phenolic acids intake in both MED countries (26\%) and non-MED countries (29\%). The major food sources of lignans were bread, crisp bread, rusks and crackers in all European regions (58-71\%). Wine was the main source of stilbenes in all regions, with a contribution of 51-57\%. Cereal products were the most important dietary source of other polyphenols, especially alkylphenols in all regions (54-80 \%).

\section{Polyphenol classes and subclasses}

Table 4 shows the contribution of classes and subclasses to total polyphenol intake. The main polyphenol classes were flavonoids (75-76\% of total intake of polyphenols) and phenolic acids (17-19\% of total intake of polyphenols) in all sexes, in both MED countries and non-MED countries. Stilbenes and lignans contributed $<1 \%$ of total polyphenol intake with mean intakes ranging from 0.03 to $0.04 \mathrm{mg}$ /day and 0.6 to $1 \mathrm{mg} /$ day, respectively, in all regions. The top three main contributors of polyphenol subclasses were flavanols (ranging from $48 \%$ in girls from MED countries to $54 \%$ in girls from non-MED countries), flavanones (ranging from $16 \%$ in girls from non-MED countries to $21 \%$ in boys from MED countries) and hydroxycinnamic acids (ranging from $16 \%$ in boys from MED countries to $17 \%$ in boys from non-MED countries), whereas alkylphenols, flavones and flavonols accounted for 1-3\% of total polyphenol intake. Other subclasses had lower proportions $(<1 \%)$.

Individual polyphenols

Of the 384 consumed individual polyphenols in the HELENA study, 20 had a mean intake higher than $1 \mathrm{mg} / \mathrm{day}, 58$ between 0.1 and 1, 90 between 0.01 and $0.1 \mathrm{mg} / \mathrm{day}$, and 216 polyphenols between $>0$ and $0.01 \mathrm{mg} / \mathrm{day}$ (Supplemental Table 1). The mean intake of the 25 most consumed individual polyphenols and their three main food sources are shown in Table 5. The three most consumed polyphenols in both sexes from all regions were proanthocyanidin polymers (>10 mers), hesperidin, and proanthocyanidin 4-6 oligomers which were consumed in quantities above 28 $\mathrm{mg} / \mathrm{day}$. Their main food sources were chocolate products, fruit and vegetable juices, apples and pears. Coffee was the main contributor to the intake of 4-caffeoylquinic acid (88.1\%) and 3-caffeoylquinic acid (78.7\%), whereas tea was the main food source of gallic acid (57.5\%) and procyanidin dimer B1 (38.9\%). A comparison between MED countries 
and non-MED countries was made for the top 10 most consumed individual polyphenols in Figure 2: all of them were higher in non-MED countries than MED countries.

\section{Discussion}

To our knowledge, this study is the first to describe a detailed intake of total polyphenols, their major food group and individual food sources in adolescents from different European countries. The influence of socio-demographic and lifestyle characteristics was also identified. Most previous studies were not focused on adolescence [12,17,27-30] and used a large heterogeneity of food consumption data, so the comparisons of polyphenol intake with other published population groups is difficult. Therefore, the use of a similar methodology for polyphenol assessment can facilitate a comparison of polyphenol intake in different studies [31,32].

\section{Overall polyphenol intake}

Reported polyphenol intake levels in literature were $1193 \pm 510 \mathrm{mg} /$ day in the French SU.VI.MAX [17], $820 \pm$ $323 \mathrm{mg} /$ day in a Spanish population at high cardiovascular risk [29], 1757 $\pm 696 \mathrm{mg} /$ day in the Polish arm of the HAPIEE study [27], $989 \pm 360 \mathrm{mg} /$ day in Polish adults [30], $377.5 \mathrm{mg} /$ day in Sao Paulo [10] and $1177 \mathrm{mg} /$ day in men and $1192 \mathrm{mg} /$ day in women from the European EPIC study [12]. Polyphenols intake adjusted by energy intake was also reported in previous studies, with a mean value of $377 \pm 3.2 \mathrm{mg} / 1000 \mathrm{kcal} / \mathrm{day}$ in the TOSCA.IT Study [11], $1199 \pm 591 \mathrm{mg} / 1000 \mathrm{kcal} /$ day in elderly of Viçosa, Brazil [33], and $854 \pm 331 \mathrm{mg} / 1000 \mathrm{kcal} /$ day [27]. Compared to these other studies, the mean polyphenol intake and the mean polyphenol intake adjusted by energy in the HELENA-study sample was lower i.e. $329 \mathrm{mg} /$ day and $160 \mathrm{mg} / 1000 \mathrm{kcal} / \mathrm{day}$. One reason for lower intakes might be the low consumption of polyphenol-rich food groups like fruit, vegetables and coffee/tea, which was the major food sources in previous studies. Indeed, total polyphenol intake probably reaches $1 \mathrm{~g}$ /day in people who eat several servings of fruit and vegetables per day [2], which is three times higher than the HELENA study as the adolescents only eat half of the recommended amount of fruit and vegetables [34]. Interesting is also the range of inter-individual differences (e.g. Supplemental Figure 1) with only few reaching the $1 \mathrm{mg} /$ day intake. The same large range was seen when comparing countries e.g. mean intake of total polyphenols was three times higher in boys from Ghent (588 $\mathrm{mg} /$ day) than in boys from Zaragoza ( $212 \mathrm{mg} /$ day).

\section{Food group contributions}

The main food contributors of polyphenols in this study were fruit (majority apple and pear), chocolate products; fruit and vegetable juices.

Interestingly, fruit and vegetables intakes in this study only reached half of the daily recommendation [35]. Especially for vegetables, this can be a reason for the lower contribution to polyphenol intakes compared to adult populations. Indeed, the daily vegetables consumption was low (164 g/person/day), and this low contribution was also noticed for flavanols in German adolescents [13]. On the other hand, fruit was an important polyphenol contributor although the consumption was similar as for vegetables (Table 2). This is in line with the Australian population where apple was the important flavonoid source for young people [14], and the contribution of fruit to flavonoid intake was higher than vegetables' contribution [36]. 
225

226

227

228

229

230

231

232

233

234

235

236

237

238

239

240

241

242

243

244

245

246

247

248

249

250

251

252

253

254

255

256

257

258

259

260

261

262

Chocolate products were the second major contributors of polyphenols in this study and adolescents consumed more sweets, which included chocolate products, than recommended [35]. Chocolate products were the third major food sources in the HAPIEE study [27], but in other studies chocolate products were not major food sources [12,17,29]. Higher chocolate consumption in the young can be because of their preferences to sweets and snacks [37].

Although coffee was the major food source of polyphenols in some studies [10,12,17,33], this was not the case in the HELENA-study sample as adolescents drink less coffee. Coffee was a minor contributor of per capita fluid intake in this study, whereas water, sugar-sweetened beverages and fruit juices were the largest contributors [38]. This can also explain why fruit juices were the third major contributions of polyphenols in the HELENA-study.

Classes, subclasses and individual polyphenols

Interestingly, 384 different individual polyphenols have been recorded, which is a similar number as in the HAPIEE study [27] and in the French SU.VI.MAX study [17] that used the same database of polyphenols. Twenty of them were consumed in higher amount than $1 \mathrm{mg} /$ day, whereas in other studies around 100 individual polyphenols were consumed in amounts greater than $1 \mathrm{mg} /$ day $[11,12,17,27]$. Some of the polyphenols consumed by the European adolescents were different, for instance there were no 5-tricosylresorcinol and 5-heptadecylresorcionol in the top 25 most consumed individual polyphenols in previous studies [12,17,27].

Flavonoids were the most consumed polyphenol class. The highest subclass contributors to total polyphenols were also in this flavonoid class: the flavanols and flavanones. The flavanols had $64 \%$ contribution to the flavonoids intake, and more specifically by proanthocyanidin polymers, proanthocyanidin 4-6 oligomers and proanthocyanidin 7-10 oligomers, which was similar as in the EPIC study [12,39]. Moreover, proanthocyanidins intake was higher in nonMED countries than in MED countries, due to higher intake of chocolate products, apple and pear consumption. In contrast, flavanones intake was higher in MED countries than in non-MED countries, due to higher consumption of fruit and vegetable juices. In MED countries, fruit were the most important food sources of flavonoids [40].

Intake of phenolic acids, especially hydroxycinnamic acids was higher also in non-MED countries than in MED countries, with coffee as the first rank contributor. This is consistent with previous studies [12,41], but the intake of phenolic acids was lower than in previous studies. Again, as mentioned above, coffee was not frequently consumed by adolescents.

Lignans and stilbenes were higher in MED countries compared to non-MED countries, but their contribution to total polyphenols i.e. below $0.5 \%$ was low, as observed earlier $[12,17,28,29]$. Lariciresinol, which was one of the three most widely consumed lignans in the EPIC study [12], was also the biggest contributor to lignans in this study, due to higher intake of bread. Current results of very low stilbenes with wine as the major contributor also agree with previous studies [11,12,29]. Consistent with an earlier study, alkylphenols (2.8-3.1\% contribution; mainly present in bread) and tyrosol (0.5-3.4 \%; present in olive oil) were the main polyphenol contributors within the other polyphenols class [12]. $\underline{\text { Socio-demographic and lifestyle determinants }}$

Socio-demographic (age, sex, European region, economic status) and lifestyle factors (BMI and alcohol use) influenced the intake of total polyphenols and polyphenol classes. Contrary to earlier studies in which men had higher absolute total polyphenol intake compared to women [10,12,33], especially for flavonoids [39,42], girls had a higher intake than boys in the HELENA-study, even after adjusting for total energy intake. This is due to higher consumption of fruit and chocolate products (the main contributors) in girls [35], while in a previous study, coffee consumption (the 
main contributor) was higher in men. Polyphenol intake increased by age, especially phenolic acid intakes, due to differential consumption of coffee and tea. In the HELENA study, adolescents aged 15.0-17.5 years old, consumed more coffee and tea than younger adolescents [35]. This age difference was also detected in Australian adolescents [14].

Intakes of total polyphenols and several polyphenol classes differed by European region. Non-MED countries had higher contributions of flavonoids and phenolic acids, which were the most contributing polyphenol classes to total polyphenols. This finding is similar as in the EPIC study [12], due to higher consumption of apple and pear, tea and coffee. Indeed, coffee was the major food source of polyphenols in non-MED countries [12,41].

In the present study, polyphenol intakes were depending on BMI, consistent with other research [12]. Polyphenol intakes were also higher in those with higher parental education, as in previous studies $[10,12]$. Indeed, parental education in this population was associated with higher diet quality [43] and healthier food choices for breakfast $[44,45]$, thus with higher intake of polyphenol rich sources like fruit and vegetables. Seemingly in contrast, adolescents who reported lower family affluence had higher polyphenol intakes, flavonoid intakes, and lignan intakes compared to those reporting greater family affluence. This might be explained by the fact that adolescents with lower family affluence consume more tea (high polyphenol content, especially flavonoids) and coffee (high polyphenol content), cakes, pies, biscuits and snacks (important polyphenol contributors in our adolescents) for breakfast [45]. Although it should be mentioned that FAS was less relevant than parental education for healthy lifestyle clustering [43,46]. Alcohol consumers also had higher polyphenol intakes. Only few adolescents consumed alcohol (23\%), but alcoholic beverages (especially wine and beer) are sources of polyphenols.

\section{Strengths and limitations}

The major strengths of this study are the large and heterogeneous sample size, which gives an approximation of the average situation in European cities [18], the use of reliable and validated 24-hour recalls [47] and the use of the Phenol-Explorer database as the most comprehensive database for polyphenols [12].

One limitation of this study is a lack of generalizability due to the cluster selection using only urban areas [18]. Missing data of Fridays and Saturdays might have induced a small bias/underestimation for alcoholic drinks which are mainly used in weekends. Also the use of self-reported data on lifestyle [47] and the lack of dietary reference intake values for dietary polyphenols [8] are limitations in this study. Finally, polyphenol intake estimation has some small difficulties like incomplete food composition data such as thearubigins [48] or proanthocyanidins concentrations [32]; some missing details in the 24-hour recall like herbs, and specific oil type; and lacking food items in the PhenolExplorer, such as palm oil, processed foods, cassava, various types of coffee, tea and honey. However, as the consumption of coffee, tea, and honey was low in this population [38]; they are almost negligible sources of polyphenols in this study.

\section{Conclusion}

For this first time, this study has provided detailed information of polyphenol intakes, its main food sources and its socio-demographic and lifestyle determinants in a diverse group of European adolescents. Total polyphenol intake (mean $329 \mathrm{mg} /$ day) was lower compared to intake of adults reported in previous studies (even after energy-adjustment). The major food sources of polyphenols in adolescents were fruit, chocolate products; and fruit and vegetable juices. Polyphenol intake differed largely among countries, especially with lower overall intakes in MED compared to non- 
MED countries, although both regions had the same major food contributors. In the major food contributors, fruit was confirmed as in adult populations but chocolate and cakes/biscuits seemed specific ones in adolescents compared to adult samples. Other important determinants were sex, age, BMI, socio-economic status and alcohol use. Overall, these results show the importance of promoting a healthier diet intake in adolescents with e.g. more fruit, vegetables and nuts to increase the currently low polyphenol intakes. The discussed determinants and polyphenol types already point to some important population groups that need to be prioritized and targeted in future public health initiatives. After all, polyphenol intake might ameliorate the future health of these youngsters.

\begin{abstract}
Financial support The HELENA Study was carried out with the financial support of the European Community Sixth RTD Framework Programme (Contract FOODCT-2005-007034). The writing group takes sole responsibility for the content of this article. The European Community is not liable for any use that may be made of the information contained therein. The first author was sponsored as PhD student by Indonesia Endowment Fund for Education (LPDP, Indonesia)

Acknowledgements We would like to thank all fieldworkers and all participating adolescents. We acknowledge the work of the Phenol explorer team.

Author's contribution R.W. Wisnuwardani formulated the research question, has analysed the data, prepared the estimation of polyphenols, and wrote a draft of the paper. N. Michels helped in refining the research question, setting up the database, analyzing the data and did editing of the first draft. N. Michels, S. De Henauw and L.A. Moreno are PhD supervisors of R.W. Wisnuwardani; L.A. Moreno was the coordinator of the HELENA project. From the International Agency for Research on Cancer, we received help from A. Scalbert, V. Knaze and I. Huybrechts in the linking to their Phenol-Explorer database containing the polyphenol concentrations in food items. All other authors were involved in the HELENA project (coordinator or data collection in their country; this was a European study in 10 centers). All authors have read the draft and agreed on the final version.
\end{abstract}

Conflict of interest The authors declare that they have no conflict of interest.

\title{
REFERENCES
}

1. Perez-Jimenez J, Neveu V, Vos F, Scalbert A (2010) Systematic analysis of the content of 502 polyphenols in 452 foods and beverages: an application of the phenol-explorer database. J Agric Food Chem 58 (8):4959-4969. doi:10.1021/jf100128b

2. Manach C, Scalbert A, Morand C, Remesy C, Jimenez L (2004) Polyphenols: food sources and bioavailability. Am J Clin Nutr 79 (5):727-747

3. Williamson G, Manach C (2005) Bioavailability and bioefficacy of polyphenols in humans. II. Review of 93 intervention studies. Am J Clin Nutr 81 (1 Suppl):243S-255S

4. Vauzour D, Rodriguez-Mateos A, Corona G, Oruna-Concha MJ, Spencer JP (2010) Polyphenols and human health: prevention of disease and mechanisms of action. Nutrients 2 (11):1106-1131. doi:10.3390/nu2111106

5. Grosso G, Stepaniak U, Micek A, Kozela M, Stefler D, Bobak M, Pajak A (2017) Dietary polyphenol intake and risk of hypertension in the Polish arm of the HAPIEE study. Eur J Nutr. doi:10.1007/s00394-0171438-7

6. Rizzi F, Conti C, Dogliotti E, Terranegra A, Salvi E, Braga D, Ricca F, Lupoli S, Mingione A, Pivari F, Brasacchio C, Barcella M, Chittani M, D'Avila F, Turiel M, Lazzaroni M, Soldati L, Cusi D, Barlassina C (2016) Interaction between polyphenols intake and PON1 gene variants on markers of cardiovascular disease: a nutrigenetic observational study. J Transl Med 14 (1):186. doi:10.1186/s12967-016-0941-6

7. Tresserra-Rimbau A, Guasch-Ferre M, Salas-Salvado J, Toledo E, Corella D, Castaner O, Guo X, Gomez-Gracia E, Lapetra J, Aros F, Fiol M, Ros E, Serra-Majem L, Pinto X, Fito M, Babio N, MartinezGonzalez MA, Sorli JV, Lopez-Sabater MC, Estruch R, Lamuela-Raventos RM, investigators Ps (2016) Intake of Total Polyphenols and Some Classes of Polyphenols Is Inversely Associated with Diabetes in Elderly People at High Cardiovascular Disease Risk. J Nutr. doi:10.3945/jn.115.223610

8. Williamson G, Holst B (2008) Dietary reference intake (DRI) value for dietary polyphenols: are we heading in the right direction? Br J Nutr 99 Suppl 3:S55-58. doi:10.1017/S0007114508006867 
349

350

351

352

353

354

355

356

357

358

359

360

361

362

363

364

365

366

367

368

369

370

371

372

373

374

375

376

377

378

379

380

381

382

383

384

385

386

387

388

389

390

391

392

393

394

395

396

9. Messina M, Hilakivi-Clarke L (2009) Early intake appears to be the key to the proposed protective effects of soy intake against breast cancer. Nutr Cancer 61 (6):792-798. doi:10.1080/01635580903285015 10. Miranda AM, Steluti J, Fisberg RM, Marchioni DM (2016) Dietary intake and food contributors of polyphenols in adults and elderly adults of Sao Paulo: a population-based study. Br J Nutr 115 (6):10611070. doi:10.1017/S0007114515005061

11. Vitale $M$, Masulli $M$, Rivellese AA, Bonora $E$, Cappellini $F$, Nicolucci $A$, Squatrito $S$, Antenucci $D$, Barrea A, Bianchi C, Bianchini F, Fontana L, Fornengo P, Giorgino F, Gnasso A, Mannucci E, Mazzotti A, Nappo R, Palena AP, Pata P, Perriello G, Potenziani S, Radin R, Ricci L, Romeo F, Santini C, Scarponi M, Serra R, Timi A, Turco AA, Vedovato M, Zavaroni D, Grioni S, Riccardi G, Vaccaro O, Group TIS (2016) Dietary intake and major food sources of polyphenols in people with type 2 diabetes: The TOSCA.IT Study. Eur J Nutr. doi:10.1007/s00394-016-1355-1

12. Zamora-Ros R, Knaze V, Rothwell JA, Hemon B, Moskal A, Overvad K, Tjonneland A, Kyro C, Fagherazzi G, Boutron-Ruault MC, Touillaud M, Katzke V, Kuhn T, Boeing H, Forster J, Trichopoulou A, Valanou E, Peppa E, Palli D, Agnoli C, Ricceri F, Tumino R, de Magistris MS, Peeters PH, Bueno-de-Mesquita HB, Engeset D, Skeie G, Hjartaker A, Menendez V, Agudo A, Molina-Montes E, Huerta JM, Barricarte A, Amiano P, Sonestedt E, Nilsson LM, Landberg R, Key TJ, Khaw KT, Wareham NJ, Lu Y, Slimani N, Romieu I, Riboli E, Scalbert A (2016) Dietary polyphenol intake in Europe: the European Prospective Investigation into Cancer and Nutrition (EPIC) study. Eur J Nutr 55 (4):1359-1375. doi:10.1007/s00394-015-0950-x

13. Vogiatzoglou A, Heuer T, Mulligan AA, Lentjes MA, Luben RN, Kuhnle GG (2014) Estimated dietary intakes and sources of flavanols in the German population (German National Nutrition Survey II). Eur J Nutr 53 (2):635-643. doi:10.1007/s00394-013-0572-0

14. Johannot L, Somerset SM (2006) Age-related variations in flavonoid intake and sources in the Australian population. Public Health Nutr 9 (8):1045-1054

15. Segovia-Siapco G, Pribis P, Oda K, Sabate J (2017) Soy isoflavone consumption and age at pubarche in adolescent males. Eur J Nutr. doi:10.1007/s00394-017-1504-1

16. Biro FM, Wien M (2010) Childhood obesity and adult morbidities. Am J Clin Nutr 91 (5):1499S1505S. doi:10.3945/ajcn.2010.28701B

17. Perez-Jimenez J, Fezeu L, Touvier M, Arnault N, Manach C, Hercberg S, Galan P, Scalbert A (2011) Dietary intake of 337 polyphenols in French adults. Am J Clin Nutr 93 (6):1220-1228. doi:10.3945/ajen.110.007096

18. Moreno LA, De Henauw S, Gonzalez-Gross M, Kersting M, Molnar D, Gottrand F, Barrios L, Sjostrom M, Manios Y, Gilbert CC, Leclercq C, Widhalm K, Kafatos A, Marcos A, Group HS (2008) Design and implementation of the Healthy Lifestyle in Europe by Nutrition in Adolescence Cross-Sectional Study. Int J Obes (Lond) 32 Suppl 5:S4-11. doi:10.1038/ijo.2008.177

19. Moreno LA, Gonzalez-Gross M, Kersting $M$, Molnar D, de Henauw S, Beghin L, Sjostrom M, Hagstromer M, Manios Y, Gilbert CC, Ortega FB, Dallongeville J, Arcella D, Warnberg J, Hallberg M, Fredriksson H, Maes L, Widhalm K, Kafatos AG, Marcos A, Group HS (2008) Assessing, understanding and modifying nutritional status, eating habits and physical activity in European adolescents: the HELENA (Healthy Lifestyle in Europe by Nutrition in Adolescence) Study. Public Health Nutr 11 (3):288-299. doi:10.1017/S1368980007000535

20. Beghin L, Castera M, Manios Y, Gilbert CC, Kersting M, De Henauw S, Kafatos A, Gottrand F, Molnar D, Sjostrom M, Leclercq C, Widhalm K, Mesana MI, Moreno LA, Libersa C, Group HS (2008) Quality assurance of ethical issues and regulatory aspects relating to good clinical practices in the HELENA CrossSectional Study. Int J Obes (Lond) 32 Suppl 5:S12-18. doi:10.1038/ijo.2008.179

21. Vereecken CA, Covents $M$, Matthys $C$, Maes $L$ (2005) Young adolescents' nutrition assessment on computer (YANA-C). Eur J Clin Nutr 59 (5):658-667. doi:10.1038/sj.ejcn.1602124

22. Vereecken CA, Covents M, Sichert-Hellert W, Alvira JM, Le Donne C, De Henauw S, De Vriendt T, Phillipp MK, Beghin L, Manios Y, Hallstrom L, Poortvliet E, Matthys C, Plada M, Nagy E, Moreno LA, Group 
397

398

399

400

401

402

403

404

405

406

407

408

409

410

411

412

413

414

415

416

417

418

419

420

421

422

423

424

425

426

427

428

429

430

431

432

433

434

435

436

437

438

439

440

441

442

443

444
HS (2008) Development and evaluation of a self-administered computerized 24-h dietary recall method for adolescents in Europe. Int J Obes (Lond) 32 Suppl 5:S26-34. doi:10.1038/ijo.2008.180

23. Dehne L, Klemm C, Henseler G, Hermann-Kunz E (1999) The German Food Code and Nutrient Data Base (BLS II.2). Eur J Epidemiol 15:1107-1117

24. Currie C, Molcho M, Boyce W, Holstein B, Torsheim T, Richter M (2008) Researching health inequalities in adolescents: the development of the Health Behaviour in School-Aged Children (HBSC) family affluence scale. Soc Sci Med 66 (6):1429-1436. doi:10.1016/j.socscimed.2007.11.024

25. Cole TJ, Bellizzi MC, Flegal KM, Dietz WH (2000) Establishing a standard definition for child overweight and obesity worldwide: international survey. BMJ 320 (7244):1240-1243

26. Neveu V, Perez-Jimenez J, Vos F, Crespy V, du Chaffaut L, Mennen L, Knox C, Eisner R, Cruz J, Wishart D, Scalbert A (2010) Phenol-Explorer: an online comprehensive database on polyphenol contents in foods. Database (Oxford) 2010:bap024. doi:10.1093/database/bap024

27. Grosso G, Stepaniak U, Topor-Madry R, Szafraniec K, Pajak A (2014) Estimated dietary intake and major food sources of polyphenols in the Polish arm of the HAPIEE study. Nutrition 30 (11-12):1398-1403. doi:10.1016/j.nut.2014.04.012

28. Ovaskainen ML, Torronen R, Koponen JM, Sinkko H, Hellstrom J, Reinivuo H, Mattila P (2008) Dietary intake and major food sources of polyphenols in Finnish adults. J Nutr 138 (3):562-566

29. Tresserra-Rimbau A, Medina-Remon A, Perez-Jimenez J, Martinez-Gonzalez MA, Covas MI, Corella D, Salas-Salvado J, Gomez-Gracia E, Lapetra J, Aros F, Fiol M, Ros E, Serra-Majem L, Pinto X, Munoz MA, Saez GT, Ruiz-Gutierrez V, Warnberg J, Estruch R, Lamuela-Raventos RM (2013) Dietary intake and major food sources of polyphenols in a Spanish population at high cardiovascular risk: the PREDIMED study. Nutr Metab Cardiovasc Dis 23 (10):953-959. doi:10.1016/j.numecd.2012.10.008

30. Witkowska AM, Zujko ME, Waskiewicz A, Terlikowska KM, Piotrowski W (2015) Comparison of Various Databases for Estimation of Dietary Polyphenol Intake in the Population of Polish Adults. Nutrients 7 (11):9299-9308. doi:10.3390/nu7115464

31. Pinto P, Santos CN (2017) Worldwide (poly)phenol intake: assessment methods and identified gaps. Eur J Nutr 56 (4):1393-1408. doi:10.1007/s00394-016-1354-2

32. Zamora-Ros R, Touillaud M, Rothwell JA, Romieu I, Scalbert A (2014) Measuring exposure to the polyphenol metabolome in observational epidemiologic studies: current tools and applications and their limits. American Journal of Clinical Nutrition 100 (1):11-26. doi:10.3945/ajcn.113.077743

33. Nascimento-Souza MA, de Paiva PG, Perez-Jimenez J, do Carmo Castro Franceschini S, Ribeiro AQ (2016) Estimated dietary intake and major food sources of polyphenols in elderly of Vicosa, Brazil: a population-based study. Eur J Nutr. doi:10.1007/s00394-016-1348-0

34. Moreno LA, Gottrand F, Huybrechts I, Ruiz JR, Gonzalez-Gross M, DeHenauw S, Group HS (2014) Nutrition and lifestyle in european adolescents: the HELENA (Healthy Lifestyle in Europe by Nutrition in Adolescence) study. Adv Nutr 5 (5):615S-623S

35. Diethelm K, Jankovic N, Moreno LA, Huybrechts I, De Henauw S, De Vriendt T, Gonzalez-Gross M, Leclercq C, Gottrand F, Gilbert CC, Dallongeville J, Cuenca-Garcia M, Manios Y, Kafatos A, Plada M, Kersting M, Group HS (2012) Food intake of European adolescents in the light of different food-based dietary guidelines: results of the HELENA (Healthy Lifestyle in Europe by Nutrition in Adolescence) Study. Public Health Nutr 15 (3):386-398. doi:10.1017/S1368980011001935

36. Penczynski KJ, Herder C, Krupp D, Rienks J, Egert S, Wudy SA, Roden M, Remer T, Buyken AE (2018) Flavonoid intake from fruit and vegetables during adolescence is prospectively associated with a favourable risk factor profile for type 2 diabetes in early adulthood. Eur J Nutr. doi:10.1007/s00394-0181631-3

37. Zujko ME, Witkowska AM, Waskiewicz A, Sygnowska E (2012) Estimation of dietary intake and patterns of polyphenol consumption in Polish adult population. Adv Med Sci 57 (2):375-384. doi:10.2478/v10039-012-0026-6 
445

38. Duffey KJ, Huybrechts I, Mouratidou T, Libuda L, Kersting M, De Vriendt T, Gottrand F, Widhalm K, Dallongeville J, Hallstrom L, Gonzalez-Gross M, De Henauw S, Moreno LA, Popkin BM, group HS (2012) Beverage consumption among European adolescents in the HELENA study. Eur J Clin Nutr 66 (2):244-252. doi:10.1038/ejcn.2011.166

39. Zamora-Ros R, Andres-Lacueva C, Lamuela-Raventos RM, Berenguer T, Jakszyn P, Barricarte A, Ardanaz E, Amiano P, Dorronsoro M, Larranaga N, Martinez C, Sanchez MJ, Navarro C, Chirlaque MD, Tormo MJ, Quiros JR, Gonzalez CA (2010) Estimation of Dietary Sources and Flavonoid Intake in a Spanish Adult Population (EPIC-Spain). Journal of the American Dietetic Association 110 (3):390-398. doi:10.1016/j.jada.2009.11.024

40. Zamora-Ros R, Knaze V, Lujan-Barroso L, Romieu I, Scalbert A, Slimani N, Hjartaker A, Engeset D, Skeie G, Overvad K, Bredsdorff L, Tjonneland A, Halkjaer J, Key TJ, Khaw KT, Mulligan AA, Winkvist A, Johansson I, Bueno-de-Mesquita HB, Peeters PH, Wallstrom P, Ericson U, Pala V, de Magistris MS, Polidoro S, Tumino R, Trichopoulou A, Dilis V, Katsoulis M, Huerta JM, Martinez V, Sanchez MJ, Ardanaz E, Amiano P, Teucher B, Grote V, Bendinelli B, Boeing H, Forster J, Touillaud M, Perquier F, Fagherazzi G, Gallo V, Riboli E, Gonzalez CA (2013) Differences in dietary intakes, food sources and determinants of total flavonoids between Mediterranean and non-Mediterranean countries participating in the European Prospective Investigation into Cancer and Nutrition (EPIC) study. Br J Nutr 109 (8):1498-1507. doi:10.1017/S0007114512003273

41. Zamora-Ros R, Rothwell JA, Scalbert A, Knaze V, Romieu I, Slimani N, Fagherazzi G, Perquier F, Touillaud M, Molina-Montes E, Huerta JM, Barricarte A, Amiano P, Menendez V, Tumino R, de Magistris MS, Palli D, Ricceri F, Sieri S, Crowe FL, Khaw KT, Wareham NJ, Grote V, Li KR, Boeing H, Forster J, Trichopoulou A, Benetou V, Tsiotas K, Bueno-de-Mesquita HB, Ros M, Peeters PHM, Tjonneland A, Halkjaer J, Overvad K, Ericson U, Wallstrom P, Johansson I, Landberg R, Weiderpass E, Engeset D, Skeie G, Wark P, Riboli E, Gonzalez CA (2013) Dietary intakes and food sources of phenolic acids in the European Prospective Investigation into Cancer and Nutrition (EPIC) study. Brit J Nutr 110 (8):1500-1511. doi:10.1017/S0007114513000688

42. Chun OK, Chung SJ, Song WO (2007) Estimated dietary flavonoid intake and major food sources of U.S. adults. J Nutr 137 (5):1244-1252

43. Michels N, Vynckier L, Moreno LA, Beghin L, de la OA, Forsner M, Gonzalez-Gross M, Huybrechts I, Iguacel I, Kafatos A, Kersting M, Leclercq C, Manios Y, Marcos A, Molnar D, Sjostrom M, Widhalm K, De Henauw S (2017) Mediation of psychosocial determinants in the relation between socio-economic status and adolescents' diet quality. Eur J Nutr. doi:10.1007/s00394-017-1380-8

44. Hallstrom L, Vereecken CA, Ruiz JR, Patterson E, Gilbert CC, Catasta G, Diaz LE, Gomez-Martinez S, Gonzalez Gross M, Gottrand F, Hegyi A, Lehoux C, Mouratidou T, Widham K, Astrom A, Moreno LA, Sjostrom M (2011) Breakfast habits and factors influencing food choices at breakfast in relation to sociodemographic and family factors among European adolescents. The HELENA Study. Appetite 56 (3):649657. doi:10.1016/j.appet.2011.02.019

45. Hallstrom L, Vereecken CA, Labayen I, Ruiz JR, Le Donne C, Garcia MC, Gilbert CC, Martinez SG, Grammatikaki E, Huybrechts I, Kafatos A, Kersting M, Manios Y, Molnar D, Patterson E, Widhalm K, De Vriendt T, Moreno LA, Sjostrom M (2012) Breakfast habits among European adolescents and their association with sociodemographic factors: the HELENA (Healthy Lifestyle in Europe by Nutrition in Adolescence) study. Public Health Nutr 15 (10):1879-1889. doi:10.1017/S1368980012000341

46. Ottevaere C, Huybrechts I, Benser J, De Bourdeaudhuij I, Cuenca-Garcia M, Dallongeville J, Zaccaria M, Gottrand F, Kersting M, Rey-Lopez JP, Manios Y, Molnar D, Moreno LA, Smpokos E, Widhalm K, De Henauw S, Group HS (2011) Clustering patterns of physical activity, sedentary and dietary behavior among European adolescents: The HELENA study. BMC Public Health 11:328. doi:10.1186/1471-2458-11-328 
491 47. Vereecken C, De Henauw S, Maes L, Moreno L, Manios Y, Phillipp K, Plada M, De Bourdeaudhuij I, 492 Group HS (2009) Reliability and validity of a healthy diet determinants questionnaire for adolescents. 493 Public Health Nutr 12 (10):1830-1838. doi:10.1017/S1368980008004655

494 48. Zamora-Ros R, Knaze V, Romieu I, Scalbert A, Slimani N, Clavel-Chapelon F, Touillaud M, Perquier 495 F, Skeie G, Engeset D, Weiderpass E, Johansson I, Landberg R, Bueno-de-Mesquita HB, Sieri S, Masala G, 496 Peeters PHM, Grote V, Huerta JM, Barricarte A, Amiano P, Crowe FL, Molina-Montes E, Khaw KT, Arguelles 497 MV, Tjonneland A, Halkjaer J, de Magistris MS, Ricceri F, Tumino R, Wirfalt E, Ericson U, Overvad K, 498 Trichopoulou A, Dilis V, Vidalis P, Boeing H, Forster J, Riboli E, Gonzalez CA (2013) Impact of thearubigins 499 on the estimation of total dietary flavonoids in the European Prospective Investigation into Cancer and 500 Nutrition (EPIC) study. European Journal of Clinical Nutrition 67 (7):779-782. doi:10.1038/ejcn.2013.89 